\title{
Estimated impact of multiple conceptuses per follicle on fecundity in the bitch
}

\author{
D Steckler ${ }^{1 *}$, KGM De Cramer $^{1 \mathrm{a}}$, JO Nöthling $^{1}$ \\ ${ }^{1}$ Section of Reproduction, Department of Production Animal Studies, Faculty of Veterinary Science, University of \\ Pretoria, Private Bag X04, Onderstepoort 0110, South Africa \\ 1aPresent address: Rant-en-Dal Veterinary Clinic, Krugersdorp, South Africa \\ *Corresponding author: Daniela-steckler@gmx.de; Section of Reproduction, Department of Production Animal \\ Studies, Faculty of Veterinary Science, Private Bag X04, Onderstepoort 0110, South Africa, Tel.: +27125298218, \\ Fax: +27125298314
}

\begin{abstract}
Multiple conceptuses from one follicle due to multi-ovular follicles or monozygotic twins inflate the ratio between the numbers of conceptuses and corpora lutea and possibly the effect ascribed to experimental treatment. The aim of this study was to estimate the impact of multiple conceptuses per follicle on fecundity in the bitch. The numbers of conceptuses and corpora lutea of 105 bitches originated from 7 published experimental studies and of 132 from ovariohysterectomies done in a private practice and a welfare organisation. Ninety five bitches, producing 597 conceptuses, had at least as many conceptuses as corpora lutea; 83 had as many, 10 had one more and 2 had 2 more. Bootstrap resampling on these 95 bitches let us to conclude that $12.6 \%$ of bitches are expected to produce more oocytes that are each capable of yielding a conceptus than the number of follicles that ovulate and that $2.35 \%$ of conceptuses are expected to be in excess of the number of follicles that ovulate. Applying the results of the current study to 2 earlier studies showed that multiple conceptuses from one follicle may, at maximum, have increased the effect ascribed to prostatic fluid by 0.022 and 0.024 conceptuses per corpus luteum, which is minor in relation to the magnitude of the ascribed effects of 0.34 and 0.22 conceptuses per corpus luteum. The number of conceptuses relative to the number of corpora lutea provides a valid and precise measurement of fertility in the bitch.
\end{abstract}

Keywords: fertility, multi-ovular follicles, oocyte, monozygotic twins, corpus luteum, bitch 


\section{Introduction}

Due to the variation in ovulation rate among bitches [1-3], the relationship between the number of conceptuses and the number of corpora lutea (the latter being used as a proxy for ovulation rate) may provide a better measurement of fertility in the experimental setting than the mere number of conceptuses [2]. Follicles containing more than one oocyte, known as multi-ovular follicles (MOFs) occur in bitches [4-10]. The possibility of MOFs bring into question the validity of using the number of corpora lutea as an indication of ovulation rate and, hence, using the relationship between the number of conceptuses and the number of corpora lutea to measure fertility in bitches.

Ovariohysterectomy of the pregnant bitch enables the researcher to precisely and accurately determine the number of corpora lutea and post-implantation conceptuses [2, 3, 11-13].

The number of post-implantation conceptuses relative to the number of corpora lutea (implantation ratio) reflects the net outcome of the number of follicles that ovulated, the number of oocytes that were fertilised and the number of early embryos that died. The higher the implantation ratio in a bitch is, the smaller the effects of fertilisation failure and embryonic death will be thereon. Thus the detracting effects of fertilisation failure and embryonic death will be smallest in bitches with implantation ratios of $100 \%$ or higher, compared to bitches with lower implantation ratios.

MOFs may have up to 17 oocytes although 2 or 3 are more common [4]. MOFs are more common in mongrels than in purebred bitches [9], and their prevalence decreases with age of the bitch and with size of the follicle [4, 5]. As many as 7\% [10] to 40\% [9], of pre-antral follicles have been found to be MOFs. In contrast, only $1 \%$ of pre-antral follicles in young anoestrous bitches (1-2 years) and none in older bitches (7-11 years) contained more than one oocyte [4]. MOFs may ovulate [7]; a view being supported by reports indicating that the number of oocytes or embryos flushed from bitches was higher than the number of corpora lutea present $[8,14]$. It is unknown how many of the oocytes released by ovulation from MOFs are able to mature and be fertilised [15] as the oocytes within a MOF can be at different developmental stages, and can be viable or degenerate [6]. Research suggests that only one oocyte of good quality is contained within a MOF $[9,10]$.

As early as 1973 Anderson and Simpson [1] showed that, in 6 of 22 litters the number of conceptuses exceeded the number of corpora lutea by one. Anderson and Simpson's finding raises the question to what extent multiple conceptuses derived from a follicle (MCFAF) may have 
caused spurious outcomes of past experiments in which groups of bitches were exposed to different treatments aimed at affecting fertility. Two past studies done at this institution $[3,11]$ serve as examples. In the first Nöthling [11] inseminated 10 bitches vaginally with frozen-thawed semen to which prostatic fluid was added after thawing (Group T) and another 10 with similar semen to which no fluid was added (Group C). Group T had 93 corpora lutea and yielded 52 conceptuses whereas Group C had 107 corpora lutea and yielded 24 conceptuses. Nöthling concluded that the addition of prostatic fluid improved the fertility of vaginally inseminated frozen-thawed dog semen. In the second study Nöthling et al. [3] inseminated 12 bitches vaginally with frozen-thawed semen to which prostatic fluid was added after thawing (Group P) and another 12 with similar semen to which albumen-free Talp was added (Group Ta). Group P had 126 corpora lutea and yielded 76 conceptuses whereas Group Ta had 117 corpora lutea and yielded 45 conceptuses. Nöthling et al. [3] concluded that the addition of prostatic fluid yielded higher fertility than the addition of albumen-free Talp. The question arises to what extent the effect of prostatic fluid may have been inflated due to the occurrence of MCFAF.

The aims of Experiment 1 of the current study were (1) to estimate the overall probability of a bitch having more than one conceptus derived from a smaller number of follicles (such as 2 conceptuses derived from one follicle), (2) to estimate the overall frequency of more than one conceptus being derived from a smaller number of follicles, (3) estimate the probability of more than one conceptus derived from a smaller number of follicles in bitches with different known numbers of conceptuses and (4) estimate the probability that different numbers of bitches in a group consisting of a specified number of bitches would have at least 2 conceptuses derived from one follicle.

The aim of Experiment 2 was to determine the maximum extent to which MCFAF could have inflated the effect ascribed to prostatic fluid by Nöthling [11] and Nöthling et al. [3].

\section{Materials and methods}

\subsection{Experiment 1}

The current study was approved by the Animal Use and Care Committee of the University of Pretoria, South Africa (Project number V059/11). 
We comprehensively reviewed the literature on the topic (Section 2.1.1) and collected data from bitches undergoing routine ovariohysterectomy during pregnancy or immediately after caesarean section at a private practice and a welfare organisation (Section 2.1.2) to identify bitches with more conceptuses than corpora lutea.

\subsubsection{Collection of data from the literature}

A comprehensive literature search was conducted using the search engine of the virtual library of the Faculty of Veterinary Science, University of Pretoria, South Africa (www.library.up.ac.za/vet/virtlib.htm) and the databases PubMed, Science Direct, Scopus and CAB to identify literature related to the topic 'fertility in the bitch'. The search terms "fertility AND bitch", "ovulation rate AND bitch", "fertilisation rate AND bitch", "implantation rate AND bitch", "early embryonic death AND bitch", "foetal death AND bitch", "multi-ovular follicles AND bitch", “insemination AND bitch”, “corpus luteum AND bitch”, “ovulation AND bitch", "fertilisation AND bitch" and others to include all publications addressing the topic of fertility in the bitch. A systematic review of citations in the retrieved papers was also carried out. Only those publications that met the criteria below were used to determine the prevalence of bitches having more conceptuses than corpora lutea:

1. The number of conceptuses and the number of corpora lutea had to be recorded for each bitch.

2. The uterus was removed for inspection and the ovaries were removed and inspected or sliced to accurately count the number of corpora lutea.

3. The time at which the reproductive organs were removed was stated.

The numbers of conceptuses and corpora lutea each bitch had as collected from the literature were recorded as Subset A.

\subsubsection{Collection of data from bitches that underwent ovariohysterectomy at a private practice and at a welfare facility}

The reproductive organs used in the present study were collected at a private small animal practice as well as an animal welfare organisation from bitches that were destined for ovariohysterectomy during pregnancy, which was incidental, or immediately after caesarean section in bitches from which owners no longer wished to breed. 
Anaesthesia and surgery were done according to generally approved and recommended methods. As premedication $7 \mu \mathrm{g} / \mathrm{kg}$ of medetomidine HCL (Zoetis Animal Health, Sandton, South Africa) was administered intravenously. Anaesthesia was induced by intravenously administered propofol (Propofol ${ }^{\circledR} 1 \%$, Fresenius Kabi AG, Bad Homburg v.d.H., Germany) at a dose of $1-2 \mathrm{mg} / \mathrm{kg}$ and maintained with sevoflurane (1-2\%) (Safeline Pharmaceuticals, Northcliff, South Africa) in oxygen.

Death of the embryos or foetuses during ovariohysterectomy in pregnant bitches was humane as it occurred within a few minutes after the blood supply to the uterus was ligated, which happened while they were fully anaesthetised. During surgery, care was taken not to damage the ovaries or the structures they contained by crushing or pinching them with instruments or rough handling. After excision the ovaries placed in properly labelled bottles with $10 \%$ formalin. After its removal the uterus of pregnant bitches was opened and the number of post-implantation conceptuses recorded. In bitches that underwent caesarean section the number of puppies and dead foetuses was recorded.

The same person dissected all ovaries and counted the corpora lutea. Formalin-fixed ovaries were each cut into slices 1-2 mm thick. Care was taken to assess whether any corpus luteum seen on the second and subsequent slices formed part of a new structure or whether it was part of a corpus luteum counted in previous slices. The number of corpora lutea in the ovaries of each bitch was recorded.

The numbers of conceptuses and corpora lutea collected from bitches that underwent ovariohysterectomy at the private practice and welfare organisation were recorded as Subset B.

\subsubsection{Data analysis}

Those 95 bitches that each had at least as many conceptuses as corpora lutea were used for bootstrap resampling, replacing the observations that were drawn before the next sample was drawn, as described below towards Aims (1) to (4), respectively:

Aim 1: Twenty thousand samples of 95 bitches each were drawn from the 95 bitches that had as many or more conceptuses as corpora lutea. (The data file for this bootstrap sampling contained 95 observations, one for each bitch, with a dichotomous variable holding the value of 0 if a bitch had as many conceptuses as corpora lutea or one if she had more.) For each sample the proportion 
of bitches with more conceptuses than corpora lutea was determined. The mean and $95 \%$ confidence interval of these 20000 proportions was then determined.

Aim 2: Bootstrap sampling was also used to estimate the probability of conceptuses being in excess of the number of corpora lutea that bitches have. To do this we first expanded the data file with 95 observations (one per bitch with at least as many conceptuses as corpora lutea) on the number of conceptuses each bitch had. This resulted in a data file with 597 observations (one for each conceptus in each of 95 bitches). We generated another variable that took the value of 0 for each conceptus in a bitch up to the number of corpora lutea she had and one for each additional conceptus that was in excess of the number of corpora lutea she had. Twenty thousand bootstrap samples of 597 conceptuses each were drawn from the 95 clusters of conceptuses, where the conceptuses of each bitch formed a cluster. For each of the 20000 samples the number of observations drawn from each cluster was equal to the cluster size. From the proportion of conceptuses in each sample that were in excess of the number of corpora lutea in the sample, we generated the overall mean probability—with its $95 \%$ confidence interval—of conceptuses being in excess of the number of corpora lutea in bitches with at least as many conceptuses as corpora lutea.

Aim 3: The same dichotomous variable in the same file with 597 observations (each representing a conceptus) used for Aim 2 was used for Aim 3. We assumed that conceptuses in excess of the number of corpora lutea a bitch had were randomly distributed among litters and independent of factors such as breed, age of bitch and others. Given this assumption, we bootstrapped 20000 samples of 5 conceptuses each from the 597 observations. Each sample represented a litter of 5 . For each sample the sum, representing the number of conceptuses among the 5 that were in excess of the number of corpora lutea were determined. From these samples the probability of litters of 5 having 1, 2, 3, 4 or 5 conceptuses in excess of the numbers of corpora lutea were estimated. The same was done for larger litters, up to a maximum of 15 .

Aim 4: The data file and dichotomous variable used for Aim 1 were used to bootstrap 20000 samples of 10 bitches each from the 95 with at least as many conceptuses as corpora lutea in order to estimate the probability of such groups having no, 1, 2 or more bitches with more conceptuses than corpora lutea. The same was then done for various other group sizes from 20 to 95 bitches. 


\subsection{Experiment 2}

The results of Experiment 1 were used to determine the extent to which the effect on fertility that had been ascribed to experimental treatment in two earlier studies by Nöthling [11] and Nöthling et al. [3] was inflated by MCFAF. In these studies the effect of prostatic fluid on the fertility of bitches inseminated with frozen-thawed dog sperm was measured in terms of the number of conceptuses in relation to the number of corpora lutea in each bitch. To do so the results of Aim 3 , namely the probability that bitches with at least as many conceptuses as corpora lutea and known numbers of conceptuses would have specific numbers of conceptuses in excess of the number of corpora lutea they have, as reported in Nöthling [11] and Nöthling et al. [3].

\subsubsection{Methods with respect to Nöthling [11]:}

The maximum inflation of the effect of prostatic fluid caused by follicles each yielding more than one conceptus would have occurred when no follicle in Group C yielded more than one conceptus and a maximum number of follicles yielded more than one conceptus in Group T. We assumed that these 2 events were independent and that the probability of both occurring had to be larger than $1 \%$.

Group C had 10.7 (round to 11) corpora lutea per bitch and Group T 9.3 (round to 9).

Two virtual groups were first created. The first (Group VC) had the same number of bitches as Group $\mathrm{C}$ and a number of follicles that ovulated equal to the number of corpora lutea in Group C. Group VC, however, had at least as many conceptuses as follicles that ovulated. The second virtual group (Group VT) had the same number of bitches as Group $\mathrm{T}$ and a number of follicles that ovulated equal to the number of corpora lutea in Group T. Group VT, however, had at least as many conceptuses as follicles that ovulated.

The probability $\left(\mathrm{P}_{\operatorname{minVC}}\right)$ of finding no follicle among the 10 Group VC bitches that yielded more than one conceptus, assuming a population probability of 0.76 (Table 4) and a binomial distribution, was found using the Stata command bitesti 100 0.76, detail.

According to Table 4 the probabilities of the follicles of a bitch in Group VT collectively

yielding 1, 2 or 4 conceptuses in excess of the number of follicles they derived from are 0.17 , 0.01 and 0.01 , respectively. The probability of a Group VT bitch yielding more conceptuses than she had follicles that ovulated is therefore 0.19 . The maximum number of Group VT bitches that each yielded more conceptus than follicles that ovulated $\left(\mathrm{B}_{\max \mathrm{VT}}\right)$, as well as the probability of 
that maximum occurring $\left(\mathrm{P}_{\max }\right)$ was determined, constraining $\mathrm{P}_{\max V T}$ such that $\mathrm{P}_{\operatorname{minVC}} \times \mathrm{P}_{\operatorname{maxVT}}$ $\geq 0.01$, which is equivalent to $\mathrm{P}_{\operatorname{maxVT}} \geq 0.01 / \mathrm{P}_{\operatorname{minVC}}$. To determine $\mathrm{B}_{\operatorname{maxVT}}$ the command bitesti 10 n 0.19, detail was repeatedly used, with $n$ representing the number of Group VT bitches that have more conceptuses than the follicles they derived from. The command was repeatedly run, every time increasing $n$ by one, starting at zero and ending at the largest value of $n$ that occurs with a probability $\geq \mathrm{P}_{\operatorname{maxVT}}$, with the final value of $n$ being equal to $\mathrm{B}_{\operatorname{maxVT}}$. The number of conceptuses that may have occurred in Group VT that were in excess of one per follicle that ovulated $\left(\mathrm{C}_{\text {excessvT }}\right)$ was calculated as

$\left(1 \times(17 / 19) \times B_{\max V T}\right)+\left(2 \times(1 / 19) \times B_{\max V T}\right)+\left(4 \times(1 / 19) * B_{\max V T}\right)$.

Group T had 52 conceptuses and 93 corpora lutea. The results of Group VT were used to calculate the maximum number of conceptuses among the 52 of Group $\mathrm{T}$ that were in excess of the number of follicles in Group $\mathrm{T}$ that yielded conceptuses $\left(\mathrm{C}_{\text {excess } \mathrm{T}}\right)$. $\mathrm{C}_{\text {excess } \mathrm{T}}$ was calculated as $C_{\text {excessVT }} \times 52 / 93$.

The maximum possible inflation of the effect of prostatic fluid as reported by Nöthling [11] due to follicles each yielding more than one conceptus, expressed as conceptuses per corpus luteum, was calculated as $C_{\text {excessT }} / 93$.

\subsubsection{Methods with respect to Nöthling et al. [3]:}

Group Ta had 9.75 (round to 10) corpora lutea per bitch and Group P 10.5 (round to 11). The same principles were applied as for Nöthling [11] using 2 virtual groups: virtual group VTa (albumenfree Talp added) and virtual group VP (prostatic fluid added). The minimum number of conceptuses that may have been present in Group Ta that were derived from follicles yielding more than one conceptus is 0 .

The probability $\left(\mathrm{P}_{\text {minVTa }}\right.$ ) of finding no follicle among the 12 Group VTa bitches that yielded more than one conceptus, assuming a population probability of 0.79 (Table 4) and a binomial distribution, was found using the Stata command bitesti 1200.79 , detail.

According to Table 4 the probabilities of the follicles in Group VP collectively yielding 1, 2 or 4 conceptuses in excess of the number of follicles they derived from are 0.21, 0.02 and 0.01 , respectively. The probability of a Group VP bitch yielding more conceptuses than she had follicles that ovulated is therefore 0.24. The maximum number of Group VP bitches that each yielded more conceptuses than follicles that ovulated $\left(\mathrm{B}_{\operatorname{maxVP}}\right)$, as well as the probability of that 
maximum occurring $\left(\mathrm{P}_{\operatorname{maxVP}}\right)$ was determined, constraining $\mathrm{P}_{\operatorname{maxVP}}$ such that $\mathrm{P}_{\operatorname{minVTa}} \times \mathrm{P}_{\operatorname{maxVP}}$ $\geq 0.01$, which is equivalent to $\mathrm{P}_{\operatorname{maxVP}} \geq 0.01 / \mathrm{P}_{\operatorname{minVTa}}$. To determine $\mathrm{B}_{\operatorname{maxVP}}$ the command bitesti 12 n 0.24, detail was repeatedly used, with $n$ representing the number of Group VP bitches that have more conceptuses than the follicles they derived from. The command was repeatedly run, every time increasing $n$ by one, starting at zero and ending at the largest value of $n$ that occurs with a probability $\geq \mathrm{P}_{\operatorname{maxVP}}$, with the final value of $n$ being equal to $\mathrm{B}_{\operatorname{maxVP}}$. The total number of conceptuses that may have occurred in Group VP that were in excess of one per follicle that ovulated $\left(\mathrm{C}_{\text {excessvP }}\right)$ was calculated as

$\left(1 \times(21 / 24) \times B_{\max V P}\right)+\left(2 \times(2 / 24) \times B_{\max V P}\right)+\left(4 \times(1 / 24) \times B_{\max V P}\right)$.

Group P had 76 conceptuses and 126 corpora lutea. The results of Group VP were used to calculate the maximum number of conceptuses among the 76 of Group P that were in excess of the number of follicles in Group $\mathrm{P}$ that yielded conceptuses $\left(\mathrm{C}_{\text {excessP }}\right)$. $\mathrm{C}_{\text {excessP was calculated as }}$ Cexcess $V P \times 76 / 126$.

The maximum possible inflation of the effect of prostatic fluid as reported by Nöthling et al. [3] due to follicles each yielding more than one conceptus, expressed as conceptuses per corpus luteum, was calculated as $C_{\text {excess }} / 126$.

All analyses were done with STATA version 14 (StataCorp, 4905 Lakeway Drive, College Station, Texas 77845 USA)

\section{Results}

\subsection{Experiment 1}

\subsubsection{Results pertaining to all bitches}

Table 1 displays the studies obtained from the literature and obtained from the private practice and the welfare organisation which met the set criteria. The 237 bitches reflected in Table 1 produced 1242 conceptuses $($ mean $=5.25)$.

Figure 1 shows the frequency distribution of the difference between the number of conceptuses and the number of corpora lutea of all 237 bitches. The graph shows a negative skewness with bitches having as many conceptuses as corpora lutea $(n=83)$ being most common, followed by 35 bitches having one less conceptus than corpora lutea. Fifty percent of all bitches studied had 
Table 1

Summary of research studies found in the literature that met the criteria as stated in Materials and Methods, as well as the cases reported in private practice and the welfare organization

\begin{tabular}{|c|c|c|c|c|c|c|c|c|c|}
\hline \multirow[b]{2}{*}{ Year } & \multirow[b]{2}{*}{ Source } & \multirow[b]{2}{*}{$\begin{array}{l}\text { Bitches } \\
\text { in study }\end{array}$} & \multirow[b]{2}{*}{ Breed } & \multirow[b]{2}{*}{$\begin{array}{l}\text { Breeding } \\
\text { method }\end{array}$} & \multirow[b]{2}{*}{$\begin{array}{l}\text { Effect of } \\
\text { treatment }\end{array}$} & \multicolumn{3}{|c|}{ Counting conceptuses and corpora lutea (CLs) } & \multirow[b]{2}{*}{$\begin{array}{l}\text { Bitch age } \\
\text { (years) }\end{array}$} \\
\hline & & & & & & $\begin{array}{l}\text { Method for } \\
\text { conceptuses }\end{array}$ & $\begin{array}{l}\text { Method } \\
\text { for CLs }\end{array}$ & $\begin{array}{l}\text { Time (days } \\
\text { after ovulation) }\end{array}$ & \\
\hline 1973 & $\begin{array}{l}\text { Anderson and } \\
\text { Simpson [1] }\end{array}$ & 22 & Beagle & Experimental $^{\mathrm{a}}$ & Optimal $^{\mathrm{c}}$ & $\begin{array}{l}\text { Ovh }^{\mathrm{e}} \text {, uterus } \\
\text { opened }\end{array}$ & $\begin{array}{l}\text { Inspection } \\
\text { and slicing }\end{array}$ & $17-49$ & $N S^{f}$ \\
\hline 1991 & Renton et al. [16] & 8 & Unknown & Experimental & Optimal & $\begin{array}{l}\text { Flushing oviducts } \\
\text { and uterus }\end{array}$ & Inspection & $5-13$ & NS \\
\hline 1995 & Nöthling [11] & 20 & $\begin{array}{l}\text { German } \\
\text { shepherd dog }\end{array}$ & Experimental & Suboptimal $^{\mathrm{d}}$ & $\begin{array}{l}\text { Ovh, uterus } \\
\text { opened }\end{array}$ & $\begin{array}{l}\text { Inspection } \\
\text { and slicing }\end{array}$ & $27-32$ & $1.2-6.8$ \\
\hline 2001 & Bysted et al. [14] & 9 & Beagle & Experimental & Optimal & $\begin{array}{l}\text { Flushing oviducts } \\
\text { and uterus }\end{array}$ & $\begin{array}{l}\text { Inspection } \\
\text { and slicing }\end{array}$ & $4-10$ & $0.75-3$ \\
\hline 2005 & Nöthling et al. [3] & 24 & $\begin{array}{l}\text { German } \\
\text { shepherd dog }\end{array}$ & Experimental & Suboptimal & $\begin{array}{l}\text { Ovh, uterus } \\
\text { opened }\end{array}$ & $\begin{array}{l}\text { Inspection } \\
\text { and slicing }\end{array}$ & $24-31$ & $1-3$ \\
\hline 2010 & Rota et al. [12] & 10 & $\begin{array}{l}\text { Beagle, Boxer, } \\
\text { crossbreed }\end{array}$ & Experimental & Suboptimal & $\begin{array}{l}\text { Ovh, uterus } \\
\text { opened }\end{array}$ & Inspection & $27-29$ & $1.5-5$ \\
\hline 2013 & Steckler et al. [13] & 12 & $\begin{array}{l}\text { German } \\
\text { shepherd dog }\end{array}$ & Experimental & Optimal & $\begin{array}{l}\text { Ovh, uterus } \\
\text { opened }\end{array}$ & $\begin{array}{l}\text { Inspection } \\
\text { and slicing }\end{array}$ & $22-36$ & $1-2.5$ \\
\hline 2013 & Private practice & 102 & Various & Routine $^{\mathrm{b}}$ & Unknown & $\begin{array}{l}\text { Ovh, uterus } \\
\text { opened or c- } \\
\text { section }\end{array}$ & $\begin{array}{l}\text { Inspection } \\
\text { and slicing }\end{array}$ & $\geq 33$ & NS \\
\hline 2013 & Welfare & 30 & Crossbreed & Routine & Unknown & $\begin{array}{l}\text { Ovh, uterus } \\
\text { opened }\end{array}$ & $\begin{array}{l}\text { Inspection } \\
\text { and slicing }\end{array}$ & $\geq 22$ & NS \\
\hline
\end{tabular}

a Experimental breeding method refers to data collected from the literature

b Routine breeding method refers to data collected in private practice and welfare with no knowledge of how the animals were bred

c Optimal treatment refers to a breeding method which allowed that the maximum fertility of the bitch could have been achieved (optimal timing, optimal sperm numbers)

d Suboptimal treatment refers to a breeding method which may have affected the maximum fertility of the bitch, such as using frozen-thawed semen intravaginally

e Ovariohysterectomy

f Not specified 
Figure 1 The difference between the number of conceptuses and the number of corpora lutea in 237 bitches

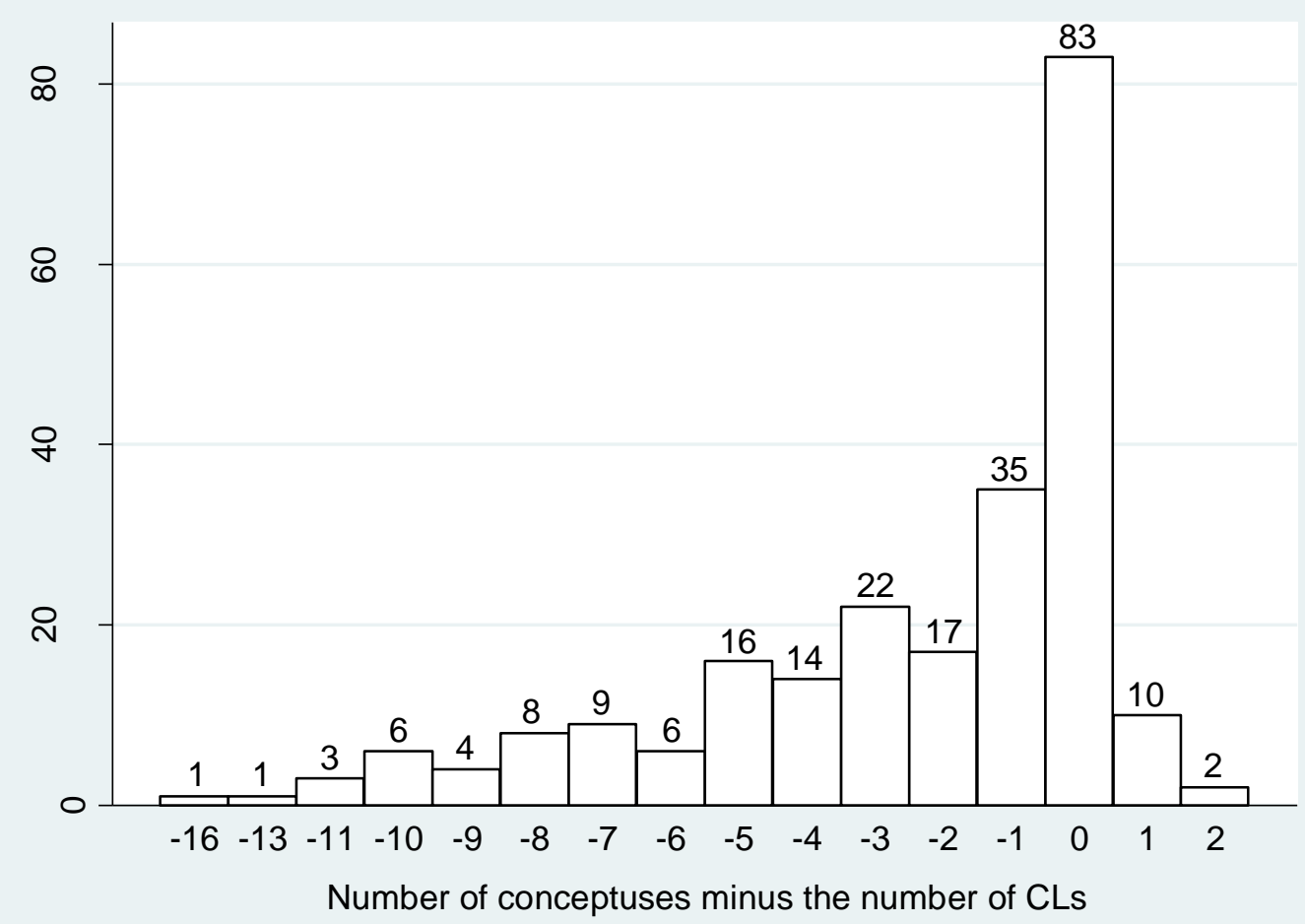


either one less or as many conceptuses as corpora lutea and 5\% had more conceptuses than corpora lutea.

\subsubsection{Results pertaining to bitches with at least as many conceptuses as corpora lutea}

Ninety five (40\%) of the 237 bitches had at least as many conceptuses as corpora lutea (Figure 1, Table 2). Table 3 shows that they produced 597 conceptuses (mean 6.3).

In the study by Anderson and Simpson [1] 13 of 22 (59\%) bitches had as many conceptuses as corpora lutea and $6(27 \%)$ had one more conceptus than corpora lutea, which is more than in any other study (Table 2).

\subsubsection{Aim 1}

On average, $12.6 \%$ (95\% CI $5.9 \%$ to $19.3 \%$ ) of bitches with at least as many conceptuses as corpora lutea are expected to have more conceptuses than corpora lutea.

\subsubsection{Aim 2}

Among bitches with at least as many conceptuses as corpora lutea, 2.35\% (95\% CI 1.08\% to $3.61 \%$ ) of conceptuses are expected to be in excess of the number of corpora lutea.

\subsubsection{Aim 3}

Considering bitches with at least as many conceptuses as corpora lutea and known numbers of conceptuses (litter sizes), Table 4 shows the expected probability having specific numbers of conceptuses in excess of their number of corpora lutea. For example, among bitches having litter sizes of 5 and no more than 5 corpora lutea, $88 \%$ are expected to have no more conceptuses than corpora lutea, $11 \%$ are expected to have one more conceptus than corpora lutea and $1 \%$ to have 2 or 3 more. As litter size increases among bitches with at least as many conceptuses as corpora lutea, so does the probability of bitches having more conceptuses than corpora lutea (Table 4).

\subsubsection{Aim 4}

Table 5 shows the expected probability of finding groups of bitches of specified sizes with different numbers of bitches having more conceptuses than corpora lutea where each bitch in the group has at least as many conceptuses as corpora lutea. For example, among 10-bitch groups, where each bitch has at least as many conceptuses as corpora lutea, $25 \%$ of the groups is expected to have no 
Table 2

Number of bitches among 95 found in the literature, in a private practice and a welfare organization that had as many, one more or 2 more conceptuses than corpora lutea

\begin{tabular}{lcccc} 
Study & As many & One more & Two more & Total \\
\hline Anderson and Simpson [1] & 13 & 6 & 0 & 19 \\
Renton et al. [16] & 2 & 0 & 0 & 2 \\
Nöthling [11] & 2 & 0 & 0 & 2 \\
Bysted et al. [14] & 6 & 0 & 1 & 7 \\
Nöthling et al. [3] & 5 & 0 & 0 & 5 \\
Rota et al. [12] & 1 & 0 & 0 & 1 \\
Steckler et al. [13] & 3 & 0 & 0 & 3 \\
Private practice & 41 & 1 & 0 & 42 \\
Welfare & 10 & 3 & 1 & 14 \\
\hline Total & 83 & 10 & 2 & 95 \\
\hline
\end{tabular}

Table 3

Total numbers of corpora lutea and conceptuses in groups of bitches with as many-, one more, and 2 more conceptuses than corpora lutea

\begin{tabular}{lcccc}
\hline & As many & One more & Two more & Total \\
\hline Number of bitches in the group & 83 & 10 & 2 & 95 \\
Number of corpora lutea & 506 & 59 & 18 & 583 \\
Number of conceptuses & 506 & 69 & 22 & 597 \\
\hline
\end{tabular}

Table 4

Probability (expressed as percentages) that bitches with at least as many conceptuses as corpora lutea and known numbers of conceptuses would have specific numbers of conceptuses in excess of the number of corpora lutea they have

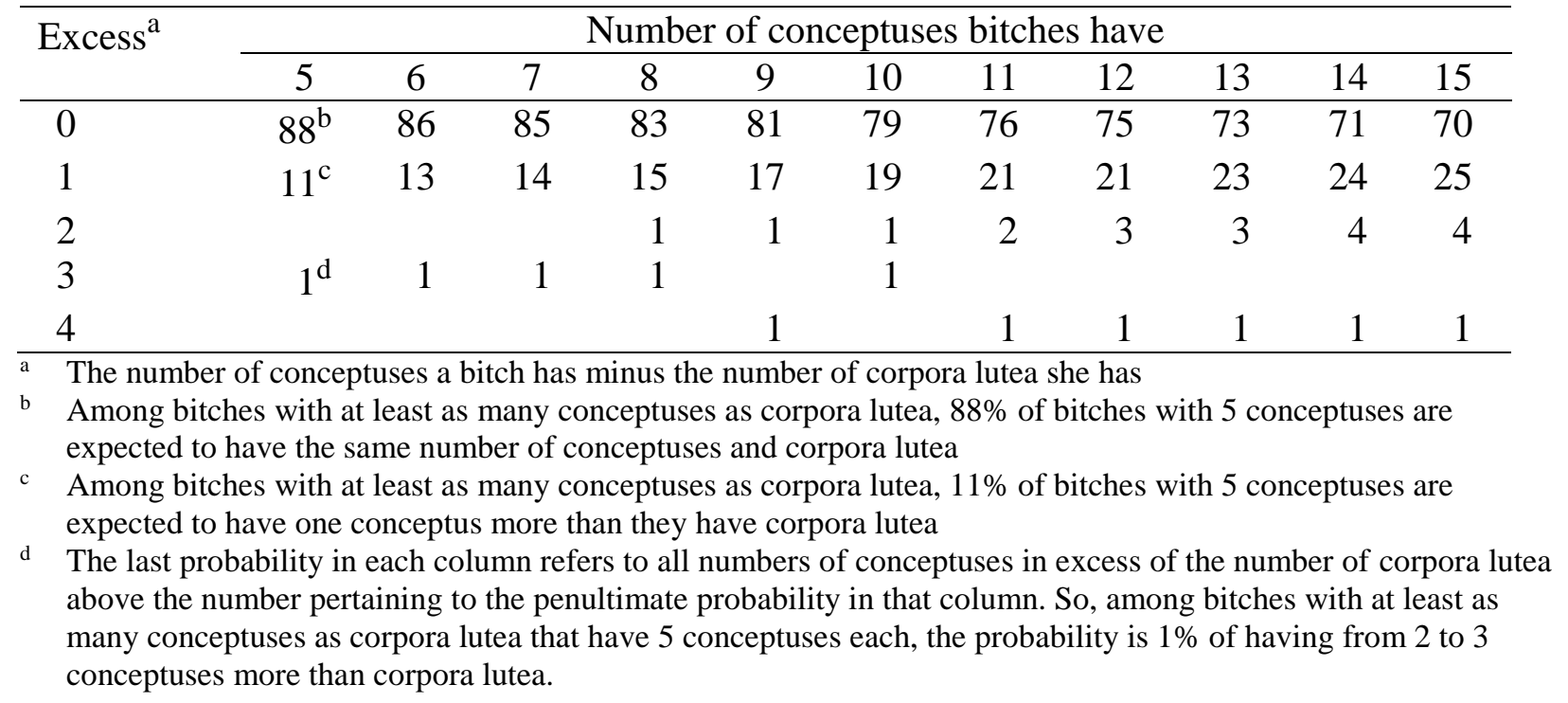


Table 5

The expected probability (expressed as percentages) of finding groups of bitches of specified sizes with different numbers of bitches having more conceptuses than corpora lutea where each bitch in the group has at least as many conceptuses as corpora lutea

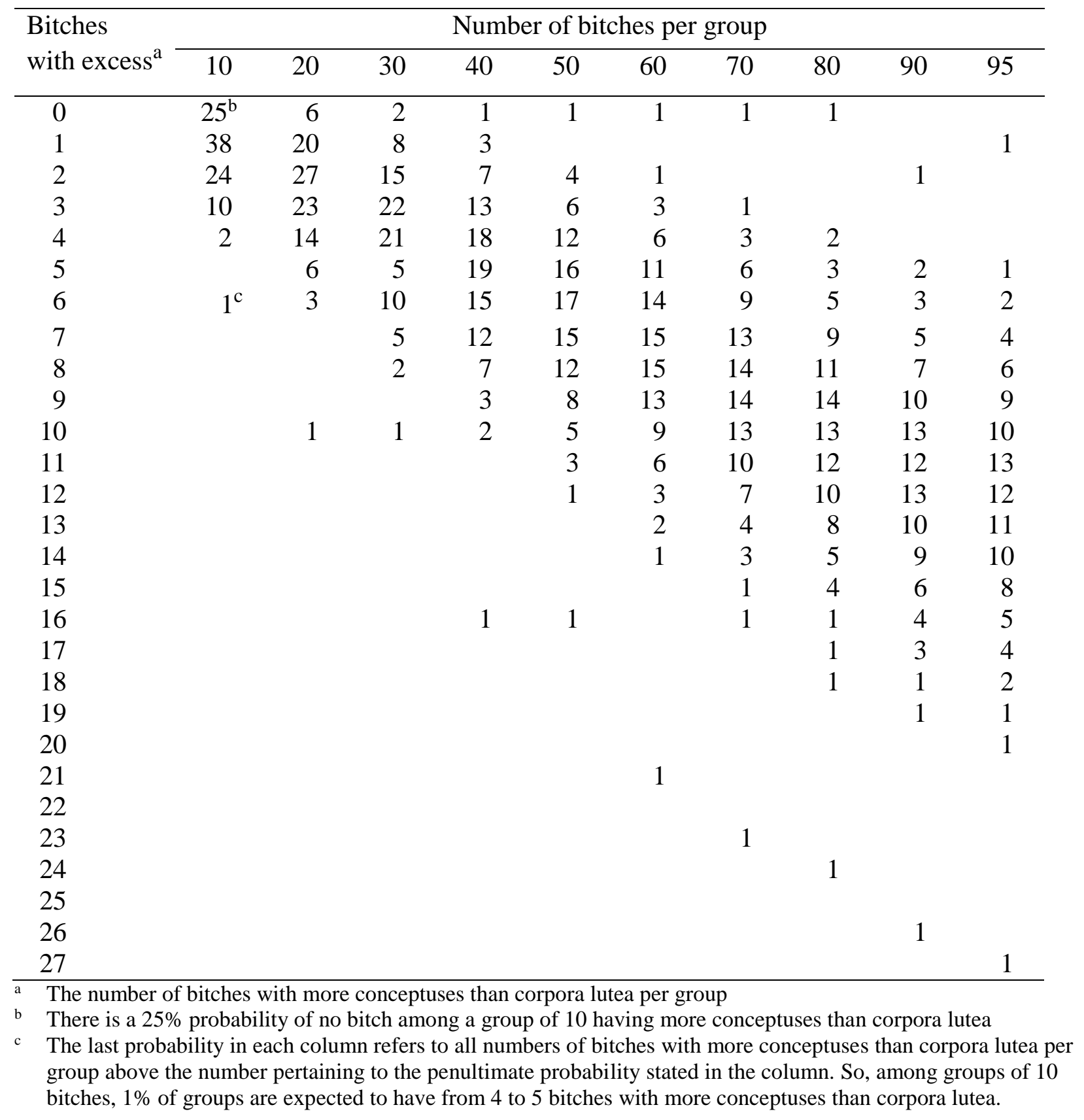


bitches with more conceptus than corpora lutea, $38 \%$ to have $1,24 \%$ to have $2,10 \%$ to have $3,2 \%$ to have 4 and $1 \%$ of groups to have between 5 and 6 bitches with more conceptus than corpora lutea. As the size of the bitch-groups increases from 10 to 95 bitches per group the number of bitches having more conceptuses than corpora lutea is also expected to increase. Table 5 further shows that, given that all bitches in a group have at least as many conceptuses as corpora lutea, the probability of having no bitch with more conceptuses than corpora lutea is $25 \%$ for groups of 10 bitches, $6 \%$ for groups of 20 bitches, $2 \%$ for groups of 30 bitches, $1 \%$ for groups of 40 bitches and lower for larger groups.

\subsection{Experiment 2}

\subsubsection{Results pertaining to Nöthling [11]:}

The probability of finding no follicle yielding more than one conceptus in Group VC $\left(\mathrm{P}_{\operatorname{minvC}}\right)$ is 0.064, from which follows that the probability of the maximum number of Group VT bitches with more conceptuses than corpora lutea occurs $\left(\mathrm{P}_{\operatorname{maxVT}}\right)$ must be at least 0.156 .

A maximum of 3 Group VT bitches $\left(\mathrm{B}_{\operatorname{maxVT}}\right)$ are expected to each yield 2, 3 or 5 conceptuses and the probability of this maximum occurring was 0.188 . (Three follicles each yielding 2,3 or 5 conceptuses means the same as 3 follicles each yielding 1, 2 or 4 conceptuses more than would have been the case under the assumption that a follicle yields one conceptus only.)

The probability of finding no bitch yielding more than one conceptuses in Group VC and, at the same time, finding the maximum of 3 bitches each yielding 1, 2 or 4 conceptuses in excess of one in Group VT is $1.2 \%$, which is larger than the required minimum of $1 \%$.

In total, Group VT may have yielded a maximum of 3.63 (round to 4) conceptuses that were in excess of one per follicle that ovulated ( $\left.\mathrm{C}_{\text {excessvT }}\right)$.

Group VT, which consisted of 10 bitches each with 9 follicles that ovulated and no fewer conceptuses, may, at maximum, have had 94 conceptuses, with the excess of 4 being ascribed to follicles yielding more than one conceptus each.

Applying this to Group $\mathrm{T}$ would mean that a maximum of 2 conceptuses among the 52 were derived from follicles that yielded more than one conceptus each $\left(\mathrm{C}_{\mathrm{excess}}\right)$. The maximum possible inflation of the effect of prostatic fluid as reported by Nöthling [11] due to follicles each yielding more than one conceptus was 0.0215 conceptuses per corpus luteum. 
Nöthling [11] reported 0.224 conceptuses per corpus luteum in Group C, to which no prostatic fluid was added, and 0.559 in Group $\mathrm{T}$, to which prostatic fluid was added, resulting in an effect ascribed to prostatic fluid of 0.335 conceptuses per corpus luteum. Subtracting the maximum possible inflation of the effect due to follicles yielding more than one conceptus results in a minimum effect of prostatic fluid of 0.314 .

\subsubsection{Results pertaining to Nöthling et al. [3]:}

The probability of finding no follicle yielding more than one conceptus in Group VTa $\left(\mathrm{P}_{\operatorname{minVTa}}\right)$ is 0.059, from which follows that the probability of the maximum number of Group VP bitches with more conceptuses than corpora lutea occurs $\left(\mathrm{P}_{\operatorname{maxVP}}\right)$ must be at least 0.169 . Group VP had a maximum of 4 bitches each yielding 2,3 or 5 conceptuses $\left(\mathrm{B}_{\operatorname{maxVP}}\right)$ and the probability of this maximum occurring was 0.183 .

The probability of finding no bitch yielding more than one conceptus in Group VTa and, at the same time, finding the maximum of 4 bitches yielding 1, 2 or 4 conceptuses in excess of one in Group VP is $1.1 \%$, which is higher than the required minimum of $1 \%$.

In total, Group VP may have yielded a maximum of 4.83 (round to 5) conceptuses in excess of one per follicle that ovulated $\left(\mathrm{C}_{\text {excessvP }}\right)$.

Group VP, which consisted of 12 bitches each with 11 follicles that ovulated and no fewer conceptuses, may, at maximum, have had 137 conceptuses, with the excess of 5 being ascribed to follicles yielding more than one conceptus each.

Group P by Nöthling et al. [3] may have had a maximum of 3 conceptuses among the 76 that were derived from follicles that yielded more than one conceptus each $\left(\mathrm{C}_{\text {excessP }}\right)$. The maximum possible inflation of the effect of prostatic fluid as reported by Nöthling et al. due to follicles each yielding more than one conceptus was 0.0238 conceptuses per corpus luteum.

Nöthling et al. [3] reported 0.385 conceptuses per corpus luteum in Group Ta, inseminated with semen to which albumen-free Talp was added, and 0.603 in Group T, inseminated with semen to which prostatic fluid was added, resulting in an effect ascribed to prostatic fluid of 0.218 conceptuses per corpus luteum. Subtracting the maximum possible inflation of the effect due to follicles yielding more than one conceptus results in a minimum effect of prostatic fluid of 0.194. 


\section{Discussion}

In addition to the studies by Anderson and Simpson [1] and Bysted et al. [14], the current study provides further proof that the number of conceptuses can exceed the number of corpora lutea.

This study shows that, among 95 bitches like the ones used in Experiment 1 with at least as many conceptuses than corpora lutea, $12.6 \%$ (95\% CI 9\% to 19.3\%) are expected to have more conceptuses than corpora lutea and 2.35\% (95\% CI 1.0108-1.0361) of conceptuses are expected to be in excess of the number of follicles they derive from. To the extent that these 95 bitches of the current study represent the general female dog population, the following 2 generalisations are made: Firstly, that $12.6 \%$ (95\% CI 9\% to 19.3\%) of bitches in general are expected to yield more oocytes that are each capable of yielding more conceptuses than the number of follicles that ovulate. Secondly, for bitches in general, that 1.0235 (95\% CI 1.0108-1.0361) oocytes per follicle that ovulate are capable of yielding a conceptus. Given the low percentage of conceptuses in excess of the number of corpora lutea the results of the current study suggest that the number of conceptuses in relation to the number of corpora found in a bitch may be used as a valid and precise indicator of her fertility.

The aims of the current study were to make inferences about the general dog population. Yet, our analyses aimed towards fulfilling these aims were done on that subset of our data pertaining to those 95 bitches that had at least as many conceptuses as corpora lutea. The data from the remaining 142 bitches, which had fewer conceptuses than corpora lutea, were not considered. Two questions arise: to what extent are the conclusions based on the 95 bitches applicable to bitches with fewer conceptuses than corpora lutea and, second, to what extent are the conclusions based on the 95 bitches applicable to bitches in general?

Uterine pathology, mating at the wrong time and subfertility of males [17] and various factors pertaining to artificial insemination such as semen quality, site of semen deposition, number of inseminations [18] and semen processing [2, 3] may result in some fertile oocytes released at ovulation not yielding conceptuses and, thereby a reduced ratio between conceptuses and corpora lutea. More than one conceptus may derive from the same follicle if a MOF releases more than one fertile oocyte at ovulation or if an embryo splits to yield monozygotic twins [19]. Unless future studies demonstrate reasons why MOFs in bitches that will eventually have fewer conceptuses than CLs are less likely to release more than one fertile oocyte at ovulation than MOFs in bitches 
that will eventually have as many or more conceptuses than CLs, one should assume that the difference in the numbers of conceptuses relative to the numbers of CLs in these 2 categories of bitches is independent of MOFs. Further, unless a reason can be demonstrated why embryos in bitches that will eventually have fewer conceptuses than CLs are less likely to split and yield monozygotic twins than embryos in bitches that will eventually have as many or more conceptuses than CLs, one should assume that the difference in the numbers of conceptuses relative to the numbers of CLs between these 2 categories of bitches is independent of monozygotic twins.

In the current study, 10 bitches each had one more conceptus than the number of follicles that ovulated (corpora lutea) and 2 bitches each had 2 conceptuses more than the number of follicles that ovulated. Taking anyone of the 10 bitches as an example, the following question arises: Did she have only one follicle that yielded 2 fertile oocytes that resulted in conceptuses, or may she have had one ovulated follicle of which the oocyte did not result in a conceptus and another follicle that yielded not 2 but 3 fertile oocytes that each resulted in a conceptus? Clearly, the latter scenario would also have produced a bitch with one more conceptus than corpora lutea. Referring to this same bitch the argument may be extended so she may have had more than one follicle of which none yielded a conceptus, combined with a variable number of follicles each yielding 2 or more conceptuses. This question should consequently also be extended to all other bitches, irrespective of whether they had more, as many or fewer conceptuses than corpora lutea. If, for example, any one of the 83 bitches that each had as many conceptuses as corpora lutea had $x$ follicles that each failed to yield a counted conceptus, she must have had $n$ follicles that collectively yielded $n+x$ conceptuses. (Such failure to yield counted conceptuses may either be due to the oocytes not being fertilised or due to conceptuses dying before being counted.) Although such a coincidental balanced occurrence of fertilisation failure or loss of conceptuses from some follicles and multiple conceptuses from some other follicles could occur it seems highly unlikely that it would have happened in a meaningful percentage of these 83 bitches.

A more plausible explanation for the perfect agreement in the number of countable conceptuses and corpora lutea in these 83 bitches is that follicles that ovulate (and form corpora lutea) generally each yield one oocyte, which, in cases of maximal fertility, would result in the same number of conceptuses than corpora lutea. If this argument is most plausible for the 83 bitches that had as many conceptuses as corpora lutea, it also is with respect to the 10 bitches that each had one more conceptus than ovulatory follicles as follows: Most likely one follicle in each of the 10 bitches 
yielded 2 conceptuses and the remaining follicles (59 among all 10 bitches) most likely each yielded one. This argument could be extended to the 2 bitches that each had 2 more conceptuses than ovulatory follicles: In each of them one follicle yielded 3 conceptuses or 2 follicles each yielded 2, with the remaining 18 follicles each yielding one conceptus.

Another explanation for an excess of conceptuses in relation to corpora lutea could be that not all corpora lutea have been counted. By slicing the ovaries in 1-2 mm intervals and taking extreme care to assess whether any corpus luteum seen on the second and subsequent slices formed part of a new structure or whether it was part of a corpus luteum seen and counted in previous slices, the current study attempted to prevent erroneous counting of corpora lutea. Although premature luteal regression has not been described in previous studies, another cause for an excess of conceptuses in relation to corpora lutea may be that one or more corpora lutea underwent such regression.

Alternatively, it might be explained by the development of monozygotic twins. Recently, Joonè et al. [19] described viable, monochorionic, monozygotic twins in the dog for the first time.

Nonetheless, we do not know how common monozygotic twins are in the dog, and it is unknown whether monozygotic twins did occur among in any of the 237 bitches or, more specifically, the 95 that had at least as many conceptuses as corpora lutea.

A shortcoming of the current study is that the data are not from a random sample of the general population of bitches, and may be biased with respect to breed and others, such as age and body weight of bitches. It is unknown what effects - if any - age, breed, or body weight might have on the probability of having more conceptuses than corpora lutea. In deriving the probability of a bitch having one or 2 more conceptuses than she has corpora lutea the current study ignores such factors and assumes that the 95 bitches are a fair representation of the general population of bitches with at least as many conceptuses as corpora lutea.

In both the earlier studies $[3,11]$ the effect of prostatic fluid may, at most, have been inflated by just over 0.02 conceptuses per corpus luteum. This decrease in effect, relative to the magnitude of the effect suggest that, at most, follicles that yielded more than one conceptus played a minor role in the studies by Nöthling [11] and Nöthling et al. [3].

As discussed above, the effect of breed or age were not assessed in the current study but could possibly be factors which may have an influence on the excess of conceptuses compared to the 
number of corpora lutea, and thus on the impact of MCFAF, which may be factors to consider when choosing experimental animals for future research. Further research should be performed in this regard.

\section{Conclusion}

Assuming that the 95 bitches of the current study are representative of all bitches with at least as many conceptuses as corpora lutea, $12.6 \%$ (95\% CI 9\% to 19.3\%) of bitches produce more oocytes capable of yielding a conceptus than the number of follicles that ovulate and, among all bitches, 1.0235 (1.0108-1.0361) oocytes per follicle that ovulate are capable of yielding a conceptus. Multiple conceptuses from a follicle played a minor role in two earlier studies and the number of conceptuses relative to the number of corpora lutea of a bitch provides a valid and precise measurement for her fertility.

\section{Acknowledgements}

The authors thank the staff of the Rant-en-Dal Veterinary Clinic and the welfare organisation for contributing valuable data for the current study.

\section{Reference list}

[1] Andersen AC, Simpson ME. The ovary and reproductive cycle of the dog (Beagle). Geron-X, Inc., Los Altos, California; 1973.

[2] Nöthling JO, Volkmann DH. Effect of addition of autologous prostatic fluid on the fertility of frozen-thawed dog semen after intravaginal insemination. J Reprod Fertil 1993; Suppl 47:329-33.

[3] Nöthling JO, Shuttleworth R, de Haas K, Thompson PN. Homologous prostatic fluid added to frozen-thawed dog spermatozoa prior to intravaginal insemination of bitches resulted in better fertility than albumin-free TALP. Theriogenology 2005; 64:975-91.

[4] Telfer E, Gosden RG. A quantitative cytological study of polyovular follicles in mammalian ovaries with particular reference to the domestic bitch (Canis familiaris). $\mathbf{J}$ Reprod Fertil 1987; 81:137-47.

[5] McDougall K, Hay MA, Goodrowe KL, Gartley CJ, King WA. Changes in the number of follicles and of oocytes in ovaries of prepubertal, peripubertal and mature bitches. J Reprod Fertil 1997; Suppl 51:25-31. 
[6] Barber MR, Lee SM, Steffens WL, Ard M, Fayrer-Hosken RA. Immunolocalization of zona pellucida antigens in the ovarian follicle of dogs, cats, horses and elephants.

Theriogenology 2001; 55:1705-17.

[7] Luvoni GC, Chigioni S, Allievi E, Macis D. Factors involved in vivo and in vitro maturation of canine oocytes. Theriogenology 2005; 63:41-59.

[8] Reynaud K, Fontbonne A, Marseloo N, Thoumire S, Chebrout M, de Lesegno CV, Chastant-Maillard S. In vivo meiotic resumption, fertilization and early embryonic development in the bitch. Reproduction (Cambridge, England) 2005; 130:193-201.

[9] Payan-Carreira R, Pires MA. Multioocyte follicles in domestic dogs: a survey of frequency of occurrence. Theriogenology 2008; 69:977-82.

[10] Reynaud K, de Lesegno CV, Chebrout M, Thoumire S, Chastant-Maillard S. Follicle population, cumulus mucification, and oocyte chromatin configuration during the periovulatory period in the female dog. Theriogenology 2009; 72:1120-31.

[11] Nöthling JO. The effect of the addition of autologous prostatic fluid on the fertility of frozen-thawed dog semen after intravaginal insemination. Masters, University of Pretoria, 1995. http://hdl.handle.net/2263/59908.

[12] Rota A, Milani C, Romagnoli S, Zucchini P, Mollo A. Pregnancy and conception rate after two intravaginal inseminations with dog semen frozen either with 5\% glycerol or 5\% ethylene glycol. Anim Reprod Sci 2010; 118:94-7.

[13] Steckler D, Nöthling JO, Harper C. Prediction of the optimal time for insemination using frozen-thawed semen in a multi-sire insemination trial in bitches. Anim Reprod Sci 2013; 142:191-97.

[14] Bysted BV, Dieleman SJ, Hyttel P, Greve T. Embryonic developmental stages in relation to the LH peak in dogs. J Reprod Fertil 2001; Suppl 57:181-6.

[15] Chastant-Maillard S, Viaris de Lesegno C, Chebrout M, Thoumire S, Meylheuc T, Fontbonne A, Chodkiewicz M, Saint-Dizier M, Reynaud K. The canine oocyte: uncommon features of in vivo and in vitro maturation. Reprod Fertil Dev 2011; 23:391-402.

[16] Renton JP, Boyd JS, Eckersall PD, Ferguson JM, Harvey MJ, Mullaney J, Perry B. Ovulation, fertilization and early embryonic development in the bitch (Canis familiaris). J Reprod Fertil 1991; 93:221-31.

[17] Johnston SD, Root Kustritz MV, Olson PNS. Canine and Feline Theriogenology. W.B. Saunders Company, Philadelphia, USA, 2001.

[18] Thomassen R, Farstad W, Krogenaes A, Fougner JA, Andersen Berg K. Artificial insemination with frozen semen in dogs: a retrospective study. J Reprod Fertil 2001; Suppl 57:341-346.

[19] Joonè CJ, De Cramer K, Nöthling JO. The first case of genetically confirmed monozygotic twinning in the dog. Reprod Dom Animal = Zuchthygiene 2016; 51:835-9. 